\title{
Coaxial Slot Antenna Design for Microwave Hyperthermia using Finite- Difference Time-Domain and Finite Element Method
}

\author{
Mario Francisco Jesús Cepeda Rubio ${ }^{1}$, Arturo Vera Hernández*,1, Lorenzo Leija Salas ${ }^{1}$, \\ E. Ávila-Navarro ${ }^{2}$ and E.A. Navarro ${ }^{3}$ \\ ${ }^{I}$ Departamento de Ingeniería Eléctrica, Sección de Bioelectrónica, Centro de Investigación y de Estudios Avanzados del \\ Instituto Politécnico Nacional, CINVESTAV-IPN, Av. IPN 2508 Colonia San Pedro Zacatenco, 07360, Mexico City, \\ Mexico \\ ${ }^{2}$ Dpto. de Ciencia de Materiales, Óptica y Tecnología Electrónica. Universidad Miguel Hernández, Elche, Spain \\ ${ }^{3}$ Dpto. de Física Aplicada y Electromagnetismo. Universitat de València, Burjassot, Spain
}

\begin{abstract}
Hyperthermia also called thermal therapy or thermotherapy is a type of cancer treatment in which body tissue is exposed to high temperatures. Research has shown that high temperatures can damage and kill cancer cells, usually with minimal injury to normal tissues. Otherwise, ablation or high temperature hyperthermia, including lasers and the use of radiofrequency, microwaves, and high-intensity focused ultrasound, are gaining attention as an alternative to standard surgical therapies. The electromagnetic microwave irradiation applied to the tumor tissue causes water molecules to vibrate and rotate, resulting in tissue heating and subsequently cell death via thermal-induced protein denaturation. The effectiveness of this technique is related to the temperature achieved during the therapy, as well as the length time of treatment and cell and tissue characteristics. Numerical electromagnetic and thermal simulations are used to optimize the antenna design and predict heating patterns. A computer modeling of a double slot antenna for interstitial hyperthermia was designed using two different numerical methods, the Finite Element Method and a Finite-Difference Time-Domain. The aim of this work is to analyze both numerical methods and finally experiments results are compared to the simulated results generated by a thermal model. Our results show that normalized SAR patterns using FEM and FDTD look broadly similar. Furthermore, the computed $60^{\circ} \mathrm{C}$ isotherm using FEM and the measured lesion diameter in ex vivo tissue results agree very well.
\end{abstract}

Keywords: Hyperthermia, microwave, computer modeling, numerical methods, cancer.

\section{INTRODUCTION}

\section{Hyperthermia}

Hyperthermia also called thermal therapy or thermotherapy is a type of cancer treatment in which body tissue is exposed to high temperatures. Research has shown that high temperatures can damage and kill cancer cells, usually with minimal injury to normal tissues [1]. By killing cancer cells and damaging proteins and structures within cells [2], hyperthermia may shrink tumors. Numerous clinical trials have studied hyperthermia in combination with radiation therapy and/or chemotherapy. These studies have focused on the treatment of many types of cancer, including sarcoma, melanoma, and cancers of the head and neck, brain, lung, esophagus, breast, bladder, rectum, liver, appendix, cervix, and peritoneal lining. Many of these studies, but not all, have shown a significant reduction in tumor size when hyperthermia is combined with other treatments [3].

Otherwise, ablation or high temperature hyperthermia, including lasers and the use of radiofrequency, microwaves, and high-intensity focused ultrasound, are gaining attention

*Address correspondence to this author at the Departamento de Ingeniería Eléctrica, Sección de Bioelectrónica, Centro de Investigación y de Estudios Avanzados del Instituto Politécnico Nacional, CINVESTAV-IPN, Av. IPN 2508 Colonia San Pedro Zacatenco, 07360, Mexico City. Mexico; Tel: +52 (55) 5747-3800, Ext 6212; E-mail: arvera@cinvestav.mx as an alternative to standard surgical therapies [4]. Each of these techniques works differently, the goal is to heat tissue to a temperature $50^{\circ} \mathrm{C}$ above can be used to destroy cells within a localized section of a tumor. Microwave ablation (MWA), uses localized heating to cause tissue necrosis. RF ablation heats the tissue by electrical resistive heating; MW ablation works on a different principle. An antenna emits microwave radiation into the tissue; this results in excitation and oscillation of polar molecules and causes frictional heating [5].

\section{Methods of Hyperthermia}

All methods of hyperthermia involve transfer of heat into the body from an external energy source and are currently under study, including local, regional, and whole-body hyperthermia. Local hyperthermia is used to heat a small area. It involves creating very high temperatures that destroy the cells that are heated. The heat may be applied using three different methods:
a) External approaches.
b) Intraluminal or endocavitary methods.
c) Interstitial techniques.

In regional hyperthermia, various approaches may be used to heat large areas of tissue, such as a body cavity, organ, or limb. Whole-body hyperthermia is used to treat me- 
tastatic cancer that has spread throughout the body. This can be accomplished by several techniques that raise the body temperature, including the use of thermal chambers or hot water blankets.

\section{Interstitial Hyperthermia}

Under anesthesia, probes are inserted into the tumor. Imaging techniques, such as ultrasound, may be used to make sure the probe is properly positioned within the tumor. The heat source is then inserted into the probe. The operating frequency is usually $2.450 \mathrm{GHz}$, which is one of the ISM (Industrial, Scientific, and Medical) dedicated frequencies. Microwave radiation has a low penetration depth in muscle tissue, on the order of $(0.012-0.12) \mathrm{m}[6]$; consequently, external applicators manifest the inability to deliver uniform thermal doses to tumor volumes. As a solution to that problem, local interstitial techniques have been developed that are proving to be safe and effective. These techniques employ implanted minimally invasive thin antennas for the delivery of local thermal doses; they are inserted through the skin, into a biocompatible catheter, under the guidance provided with an imaging monitoring procedure.

\section{Numerical Methods}

Computational electromagnetics (CEM) or electromagnetic modeling is the process that employs numerical methods to describe propagation of electromagnetic waves. It typically involves the formulation of discrete solutions using computationally efficient approximations to Maxwell's equations. There are three techniques in CEM. The finitedifference time-domain (FDTD) method belongs in the general class of grid-based differential time-domain numerical modeling methods, is based on the Yee algorithm [7] and the time-dependent Maxwell's equations are discretized using central-difference approximations to the space and time partial derivatives. This method has been used to numerically evaluate the electromagnetic radiation patterns of antennas in tissue [8], although long solution times are generally required. The method of moments (MOM) is a numerical computational method of solving linear partial differential equations, which have been formulated as integral equations. An alternative to the two techniques above is the finite element method (FEM), which has been extensively used in simulations of cardiac and hepatic radiofrequency (RF) ablation [9]. FEM models can provide users with quick, accurate solutions to multiple systems of differential equations and as such, are well suited to heat transfer problems like ablation [10].

\section{MATERIALS AND METHODOLOGY}

\section{Governing Equations}

The frequency-dependent reflection coefficient and specific absorption rate (SAR) pattern in tissue are significant for the performance of interstitial antennas. The frequencydependent reflection coefficient, can be expressed logarithmically as:

$$
\Gamma(f)=10 \cdot \log _{10}\left(\frac{P_{r}(f)}{P_{\text {in }}}\right)[d B]
$$

where Pin is the input power and $\mathrm{P}_{\mathrm{r}}$ indicates reflected power (W). The frequency where the reflection coefficient is mini- mum is commonly referred to as the resonant frequency and should be approximately the same as the operating frequency of the generator used. Antennas operating with high reflection coefficients can cause overheating of the feedline possibly leading to damage to the coaxial line or due to the thin outer conductor damage to the tissue [11]. SAR represents the amount of time average power deposited per unit mass of tissue $(\mathrm{W} / \mathrm{Kg})$ at any position. It can be expressed mathematically as

$$
S A R=\frac{\sigma}{\rho}|E|^{2} \quad[W / k g]
$$

where $\sigma$ is tissue conductivity $(\mathrm{S} / \mathrm{m}), \rho$ is tissue density $\left(\mathrm{kg} / \mathrm{m}^{3}\right)$ and $\mathrm{E}$ is the electric field vector [V/m]. The SAR takes a value proportional to the square of the electric field generated around the antenna and is equivalent to the heating source created by the electric field in the tissue. The SAR pattern of an antenna causes the tissue temperature to rise, but does not determine the final tissue temperature distribution directly. The tissue temperature increase results from both power and time, caused by direct MW heating (from SAR) and tissue thermal conduction. MW heating thermal effects can be roughly described by Pennes' Bioheat equation [12]:

$$
\nabla \cdot(-k \nabla T)=\rho_{b} C_{b} \omega_{b}\left(T_{b}-T\right)+Q_{m e t}+Q_{e x t}
$$

where $\mathrm{k}$ is the tissue thermal conductivity $\left(\mathrm{W} / \mathrm{m}^{\circ} \mathrm{K}\right), \rho_{\mathrm{b}}$ is the blood density $\left(\mathrm{Kg} / \mathrm{m}^{3}\right), \mathrm{C}_{\mathrm{b}}$ is the blood specific heat $\left(\mathrm{J} / \mathrm{Kg}^{\circ} \mathrm{K}\right), \omega_{\mathrm{b}}$ is the blood perfusion rate $(1 / \mathrm{s}) . \mathrm{Tb}$ is the temperature of the blood and $\mathrm{T}$ is the final temperature. $\mathrm{Q}_{\mathrm{met}}$ is the heat source from metabolism and $Q_{\text {ext }}$ an external heat source. The major physical phenomena considered in the equation are microwave heating and tissue heat conduction. The temperature of the blood is approximated as the core temperature of the body. Moreover, in ex vivo samples, $\omega_{\mathrm{b}}$ and $\mathrm{Q}_{\text {met }}$ can be neglected since no perfusion or metabolism exists. The external heat source is equal to the resistive heat generated by the electromagnetic field.

\section{Applicator Design}

Antenna geometry parameters and the slot spacing were chosen based on the effective wavelength in muscle at 2.45 $\mathrm{GHz}$ [13], which was calculated using the equation:

$$
\lambda_{e f f}=\frac{c}{f \sqrt{\varepsilon_{r}}}[m]
$$

where $\mathrm{c}$ is the speed of light in free space $(\mathrm{m} / \mathrm{s}), \mathrm{f}$ is the operating frequency of the microwave generator $(2.45 \mathrm{GHz})$, and $\varepsilon r=52.729$ is the relative permittivity of the muscle at the operating frequency according to the literature [14]. The slot spacing length corresponds to $0.25 \lambda$ eff, and $0.125 \lambda$ eff respectively, that was chose to achieve localized power deposition near the slots of the antenna. Nevertheless, due the catheter and its thickness also affect the performance of the antenna, according to [10], equation 4 only provides an inaccurate approximation for the design.

\section{Material Properties}

The antenna is based on a $50 \Omega$ UT-085 semirigid coaxial cable. The entire outer conductor is copper, in which a two 
small ring slot of width $1 \mathrm{~mm}$ are cut close to the shortcircuited distal tip of the antenna to allow electromagnetic wave propagation into the tissue. Our design uses a $1-\mathrm{mm}$ wide in each slot, which is easily fabricated, and also gives minimal power reflection [10]. The inner conductor is made from silver-plated copper wire (SPCW) and the coaxial dielectric used is a low-loss polytetrafluoroethylene (PTFE). Furthermore the antenna is encased in a PTFE catheter to prevent adhesion of the probe to desiccated ablated tissue. The dielectric properties of tissue over the $2-3 \mathrm{GHz}$ frequency range shown in Fig. (1) were measured using a precision open-ended coaxial probe technique. Measurements were obtained using a vector network analyzer (Agilent E5071B). Additionally dimensions and thermal properties for the materials and tissue are listed in Table $\mathbf{1}$.
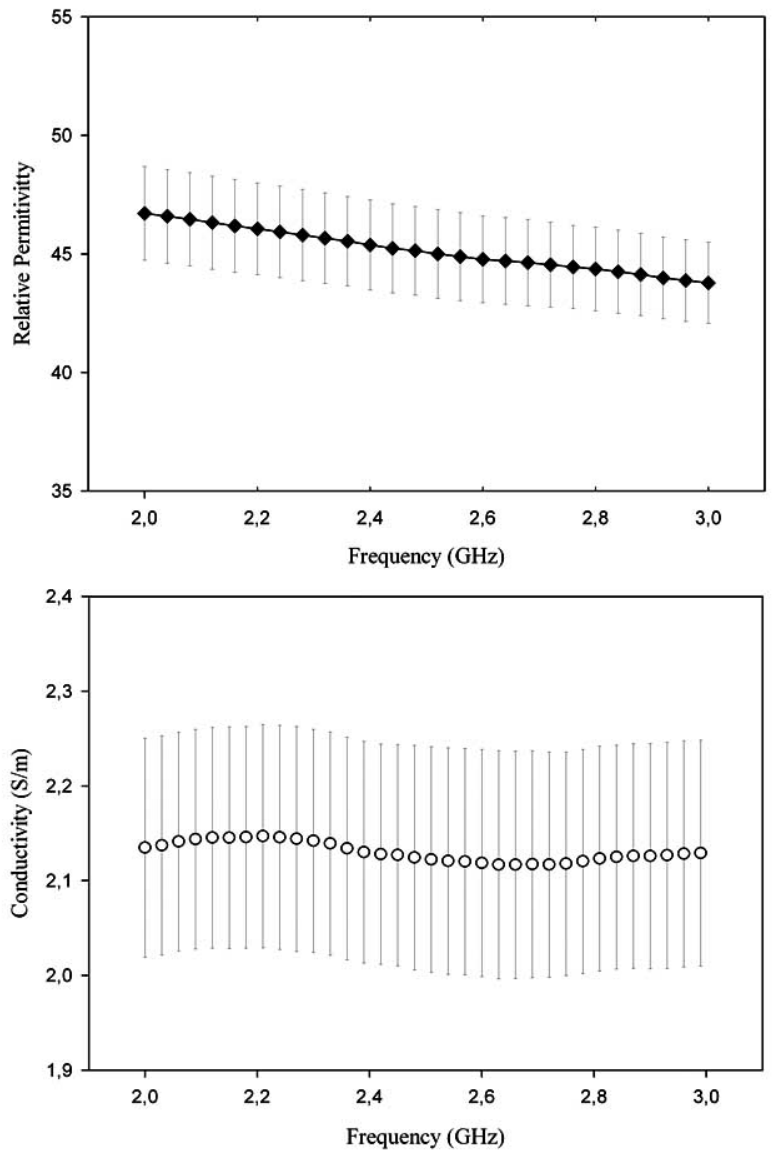

Fig. (1). Dielectric properties of ex-vivo muscle tissue.

\section{Computer Model Definition}

Due to the advantages and limitations in FEM and FDTD numerical methods and the computer modeling software, we used both numerical methods as our computer simulation tools in order to obtain a temperature distribution and SAR pattern respectively.

\section{Finite Element Method}

Effects from the antenna during the thermal ablation process are modeled using commercial software package
Table 1. Dimensions and Material Properties for the Materials and Tissue

\begin{tabular}{|c|c|}
\hline Parameter & Value \\
\hline \hline Center conductor diameter & $0.51 \mathrm{~mm}$ \\
\hline Dielectric diameter & $1.68 \mathrm{~mm}$ \\
\hline Outer conductor diameter & $2.2 \mathrm{~mm}$ \\
\hline Diameter of catheter & $1.79 \mathrm{~mm}$ \\
\hline Tissue electrical conductivity & $2.12 \mathrm{~S} / \mathrm{m}$ (mean value) \\
\hline Tissue thermal conductivity & $0.5 \mathrm{~W} / \mathrm{m} \mathrm{K}$ \\
\hline Blood density & $1060 \mathrm{Kg} / \mathrm{m} 3$ \\
\hline Specific heat of blood & $3700 \mathrm{~J} / \mathrm{Kg} / \mathrm{K}$ \\
\hline Material & Relative permittivity \\
\hline Inner dielectric of the coaxial cable & 2.03 \\
\hline Catheter & 2.60 \\
\hline Tissue & 45.20 (mean value) \\
\hline
\end{tabular}

(COMSOL Multiphysics TM), which solves partial differential equations using the FEM. The coaxial slot antenna exhibits rotational symmetry around the longitudinal axis; therefore we used an axisymmetric model, which minimized the computation time. The FEM model assumes that the coaxial slot antenna is immersed in homogeneous muscle tissue. Fig. (2) shows the axial schematics of each section of the antenna, and the interior diameters.

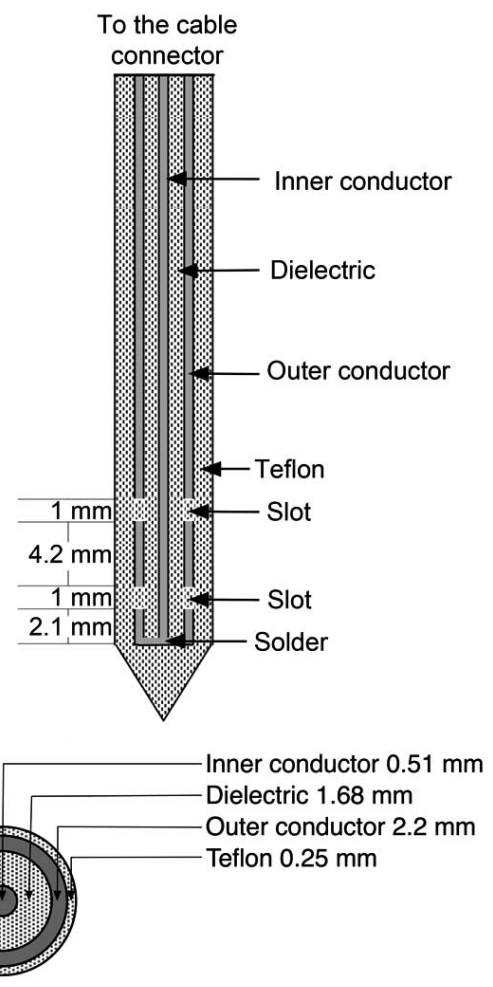

Fig. (2). Shows the axial schematics of each section of the antenna, and the interior diameters. 
The inner and outer conductors of the antenna were modeled using perfect electric conductor boundary conditions. All boundaries of conductors were set to perfect electric conductor (PEC). Boundaries along the $z$ axis were set with axial symmetry and all other boundaries were set to low reflection boundaries. Fig. (3) shows the geometry of the antenna model. Materials in the model were set to tissue, dielectric, catheter and the air was set to fill the space in the radiating slots.

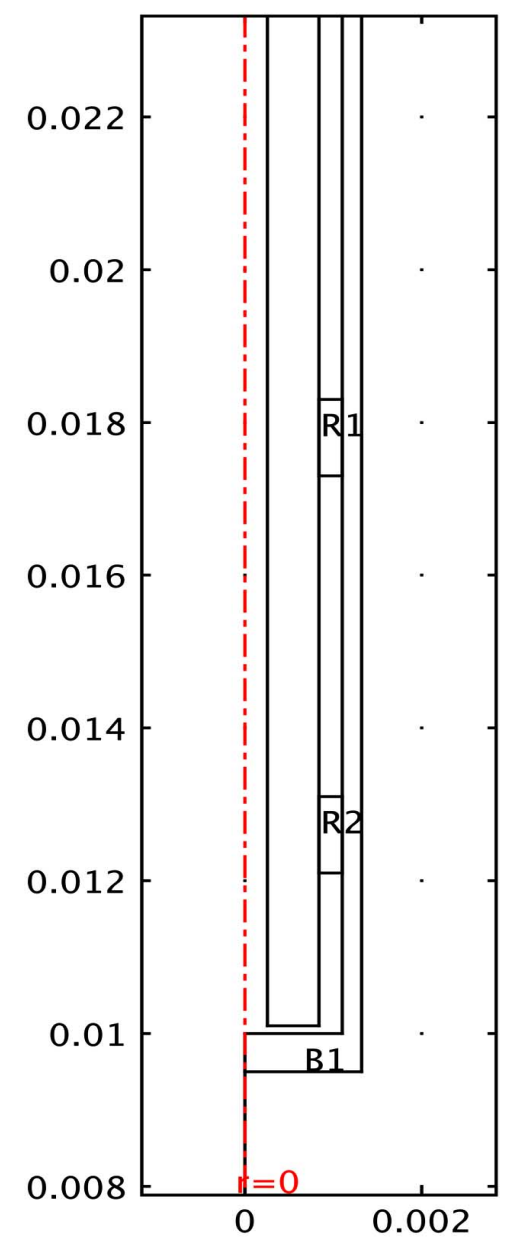

Fig. (3). Axisymmetric CEM model in the vicinity of the tip of the coaxial slot antenna.

The vertical axis corresponds to the longitudinal axis of the antenna while the horizontal axis corresponds to radial direction.

\section{Finite-Difference Time-Domain}

In this case we developed a code based on the FDTD algorithm for the simulation of the coaxial double slot antenna. This code was originally designed for the simulation of especially printed antennas [15] and recently adapted for material with losses. This is an algorithm in 3D Cartesian coordinates and full-wave in order to obtain electromagnetic fields in the time domain at any point in the simulated structure. The mesh used for the spatial discretization of the problem is configurable; therefore cell size adjustment is possible to the geometry. For the excitation a gaussian pulse was used with wide enough with the aim of obtain a frequency components at $2.45 \mathrm{GHz}$. Furthermore applying the Fast Fourier
Transform (FFT) the field distributions is calculated in any plane, and therefore the SAR is obtained. The availability of electromagnetic fields at any point in the simulated structure allows match the developed code for other physical implications, such as tissue heating.

\section{RESULTS}

\section{Finite Element Method}

The axisymmetric finite element mesh presented in Fig. (4), has been selected in order to achieve a compromise between accuracy of computation and reasonable dimensionality of the model. The mesh consists of 22009 triangular elements. Dense mesh zone has been generated in the vicinity of the tip of the antenna, where the temperature is more concentrated.

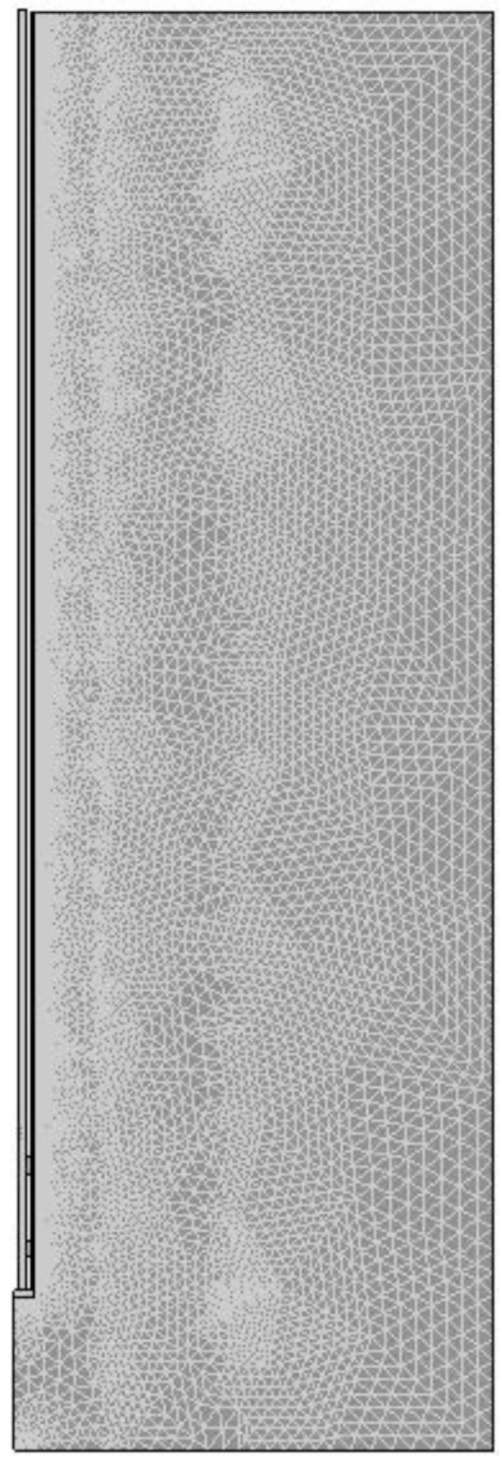

Fig. (4). Plot of the whole FEM model with mesh grids. This FEM model contains 22009 elements.

Fig. (5) shows the SAR pattern, normalized to the maximum value in $\mathrm{dB}$. Thermal model was obtained using the postprocessing features in Comsol. Fig. (6) shows the resulting steady-state temperature distribution in the tissue for an 
input microwave power of $10 \mathrm{~W}$. The black margin represents the $60{ }^{\circ} \mathrm{C}$ isotherm, which is considered lesion boundary.

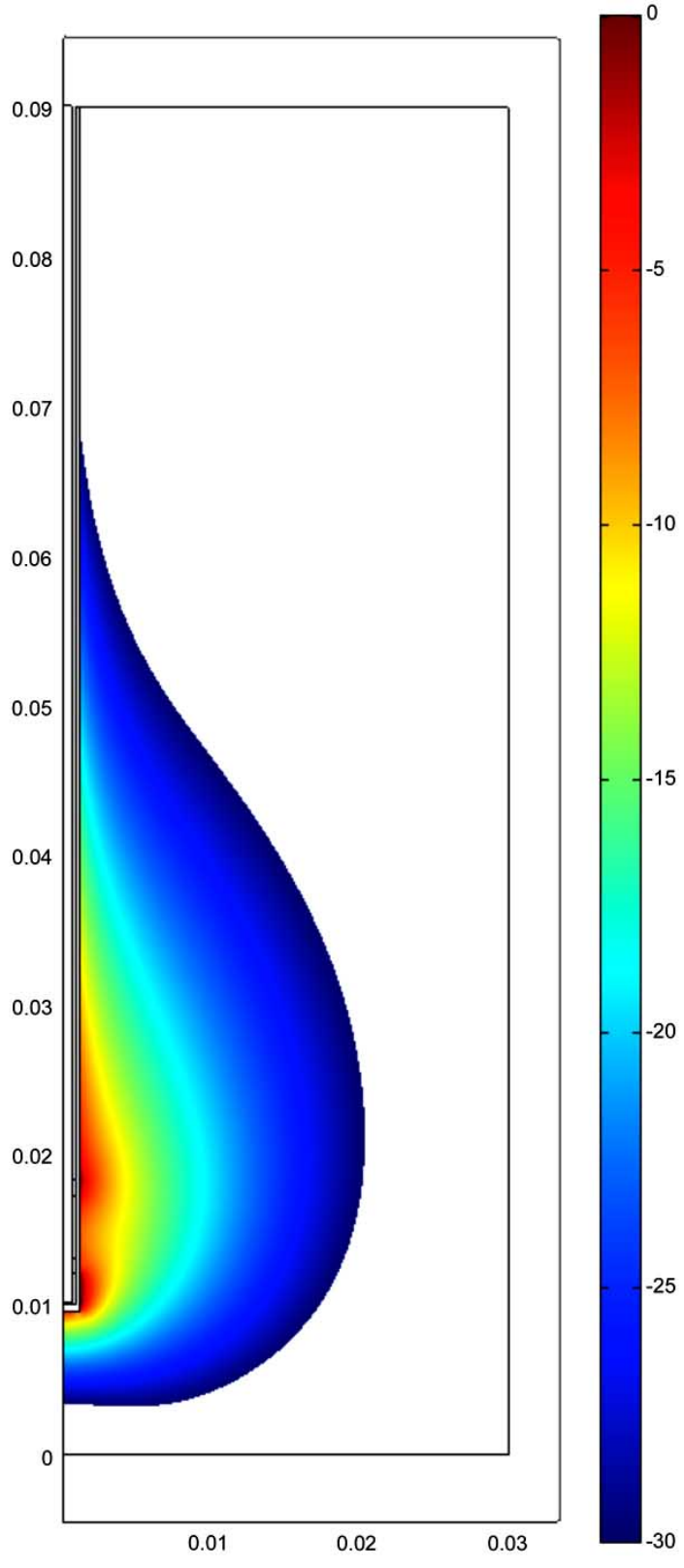

Fig. (5). SAR pattern, normalized to the maximum value in $\mathrm{dB}$. The illustration shows half the plane through the symmetry axis.

\section{Finite-Difference Time-Domain}

Fig. (7) shows the mesh used in the FDTD algorithm. As seen, the size of each cell is set depending on the geometry of the applicator to be analyzed. The highest density of mesh is just around the applicator, with a logarithmic decrease as we move away from it. The total number of cells is approximately 587,000 . In the meshing the next color code is used: the metal components are represented on black, in blue the dielectric located inside of the coaxial, in yellow the catheter and in red the two slots. The applicator is immersed in a homogeneous region simulating the human tissue.

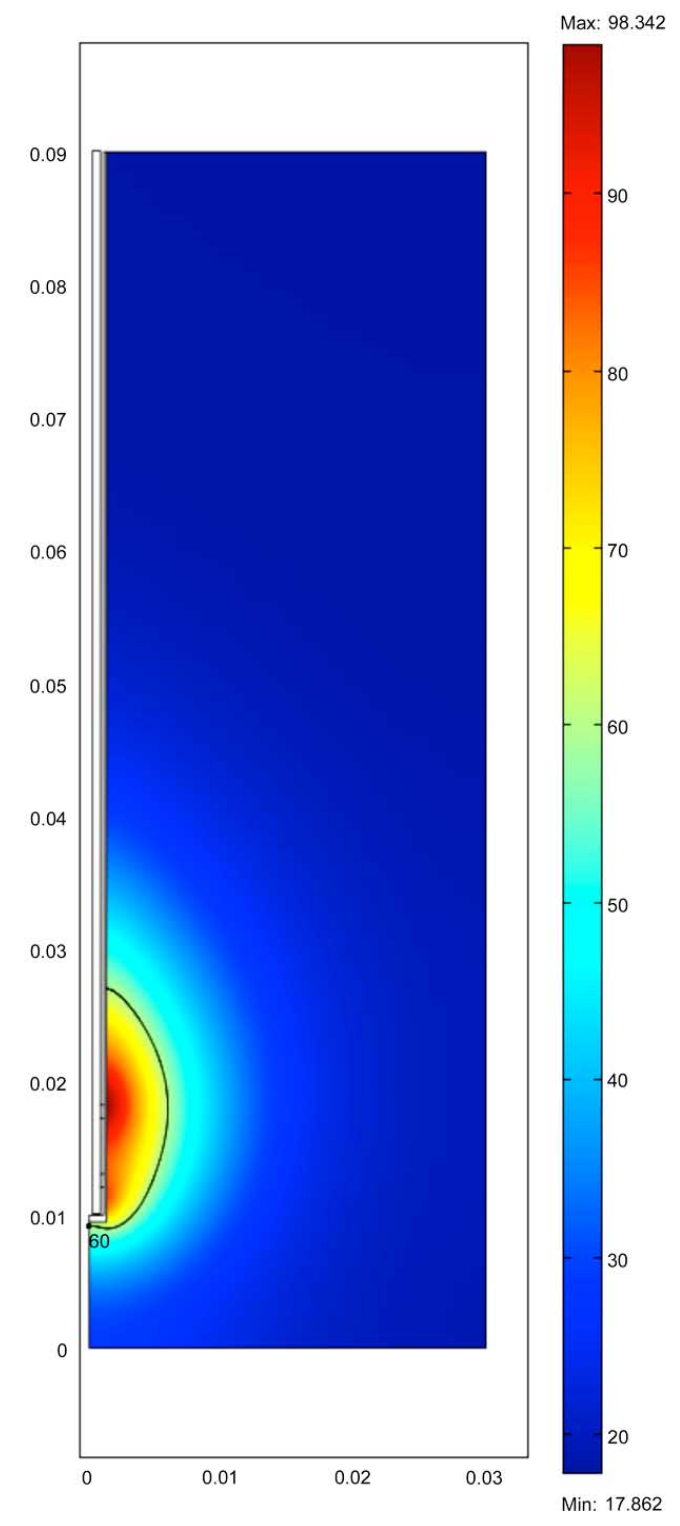

Fig. (6). Steady-state temperature distribution in the tissue and 60 ${ }^{\circ} \mathrm{C}$ isotherm obtained with FEM commercial solver. The illustration shows half the plane through the symmetry axis.

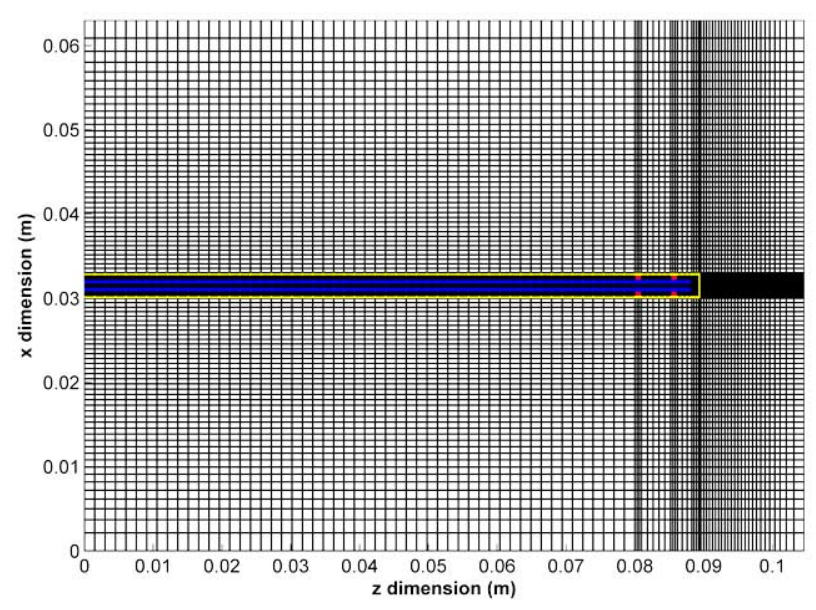

Fig. (7). Plot of the FDTD mesh model. 
Fig. (8) shows the SAR obtained with the FDTD code for the coaxial double slot applicator used.

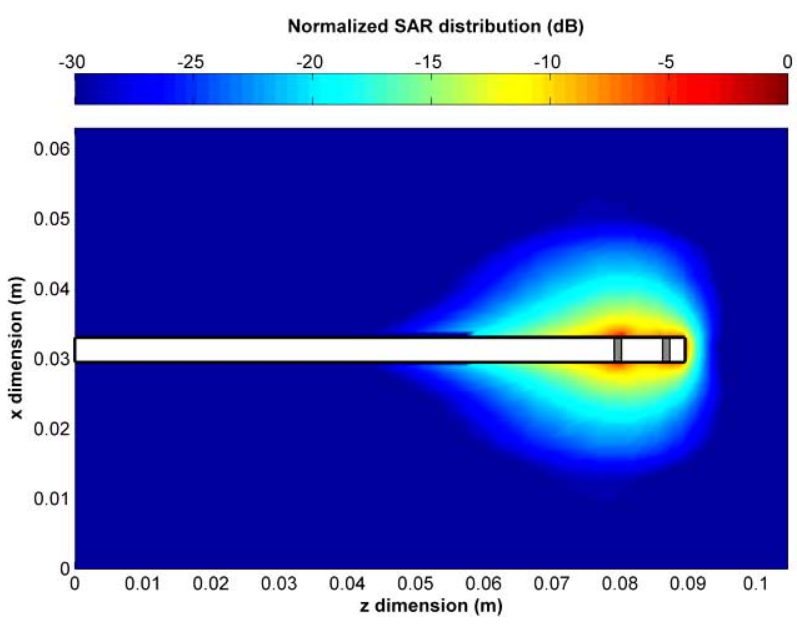

Fig. (8). SAR distribution produced by FDTD.

Figs. (9 and 10) compares results from normalized SAR pattern using FEM and FDTD computer simulations as a function of radial distance to each radiating slot.

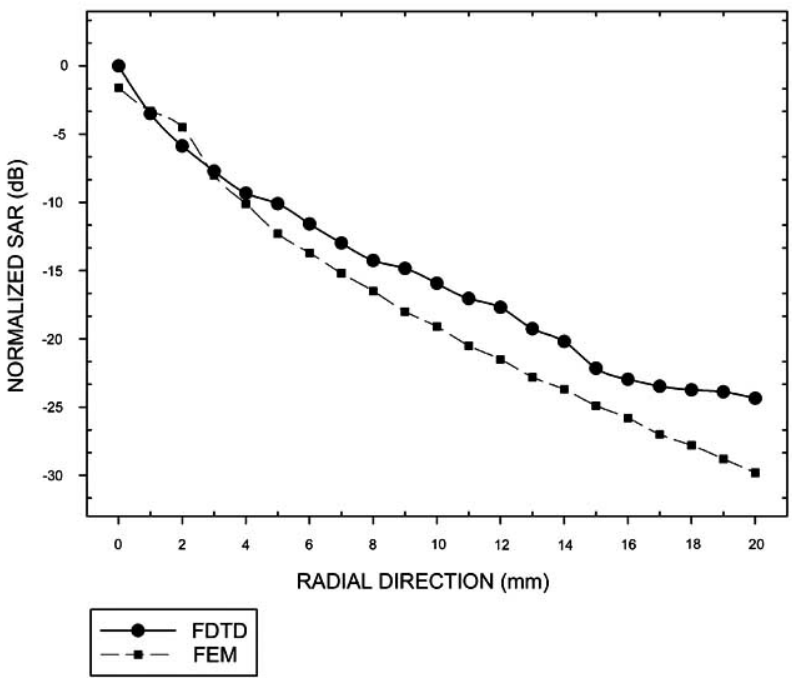

Fig. (9). Normalized SAR pattern as a function of radial distance in slot 1 using FEM (squares) or FDTD (circles) computer simulations for comparison.

\section{Model Validation}

To validate the performance of computer model, a double slot antenna was constructed from UT-85 semirigid coaxial cable and a SMB connector. Fresh swine muscle was obtained from a local slaughterhouse. In the computer model, reflection coefficient is independent of insertion depth, but this change in a real situation. Therefore prior to thermal ablation the coaxial double slot antenna was physically inserted into homogeneous regions of muscle tissue and connected to an Agilent E5071B network analyzer to measure the frequency-dependent reflection coefficient vs. insertion depth, shown in Fig. (11).

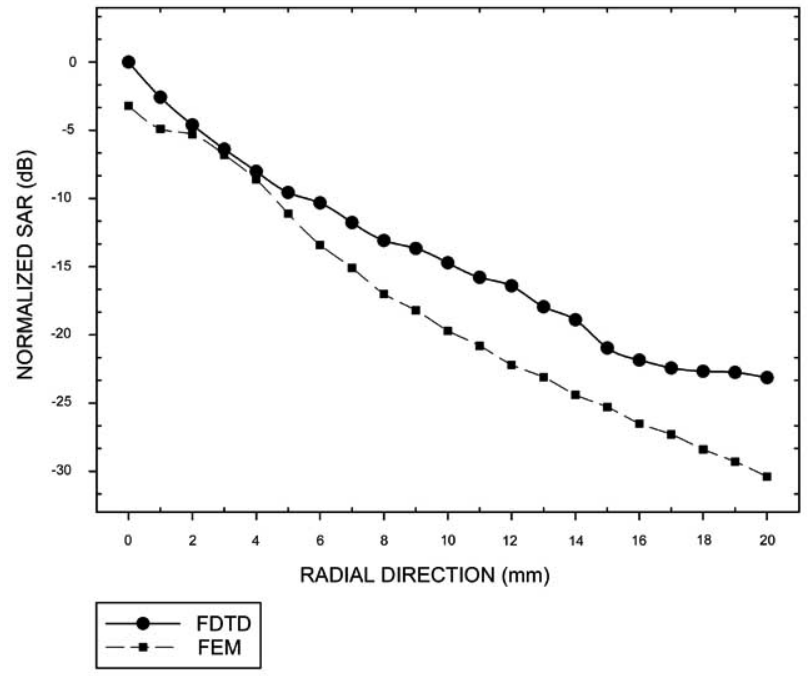

Fig. (10). Normalized SAR pattern as a function of radial distance in slot 2 using FEM (squares) or FDTD (circles) computer simulations for comparison.

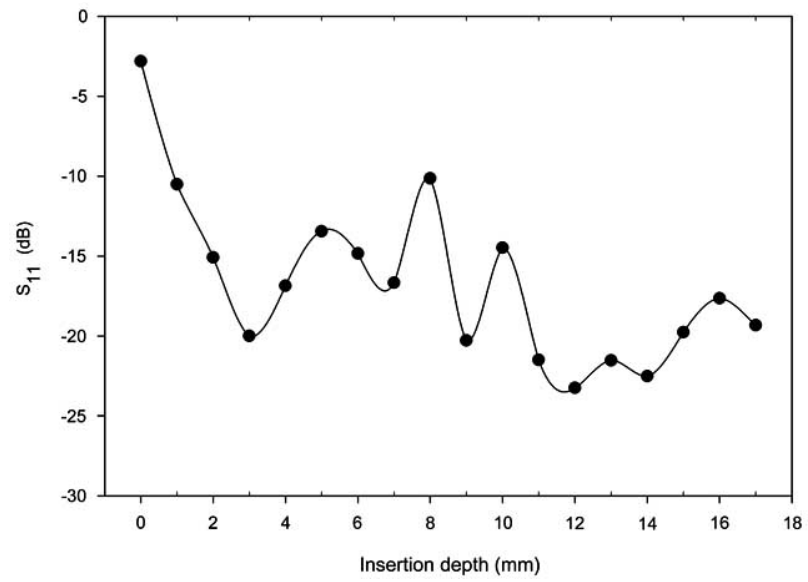

Fig. (11). Measured insertion depth vs. reflection coefficient.

High temperature hyperthermia experiments were performed at $10 \mathrm{~W}$ for $3 \mathrm{~min}$. The initial tissue temperature was 18 to $19{ }^{\circ} \mathrm{C}$. Fig. (12) shows the tissue with an ablated zone.

To determine the lesion diameter the image-processing software ImageJ Version 1.42 (National Institutes of Health) the mean lesion diameter was found to be $9.09 \mathrm{~mm}$ with a standard deviation of $0.151 \mathrm{~mm}$.

Additionally to the model validation, tissue temperature was measured during ablation (Fig. 13). Luxtron STB MAR'05 fiberoptic thermal probes were placed $5 \mathrm{~mm}$ above the antenna slots longitudinally to measure real-time temperature during hyperthermia experiment. The fiberoptic thermal probes are connected to a Luxtron 3300 Fluoroptic thermometer, which monitors the temperature and saves the data to a personal computer via a RS-232 serial cable.

The measured thermal histories at the specified locations during high hyperthermia therapy were shown in Fig. (14). 


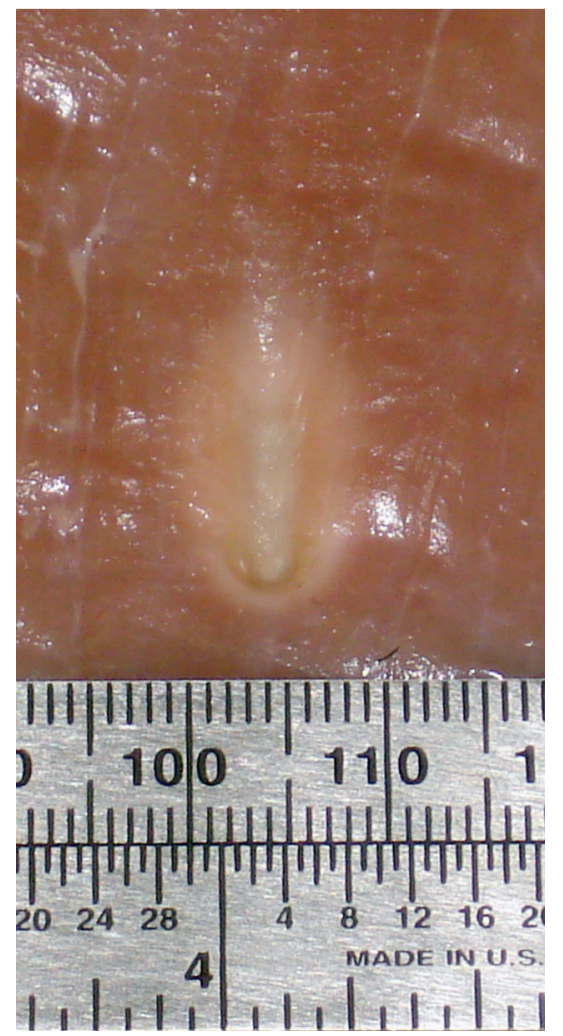

Fig. (12). A lesion created in an ex-vivo experiment at the end of a $180 \mathrm{~s}$ hyperthermia procedure.

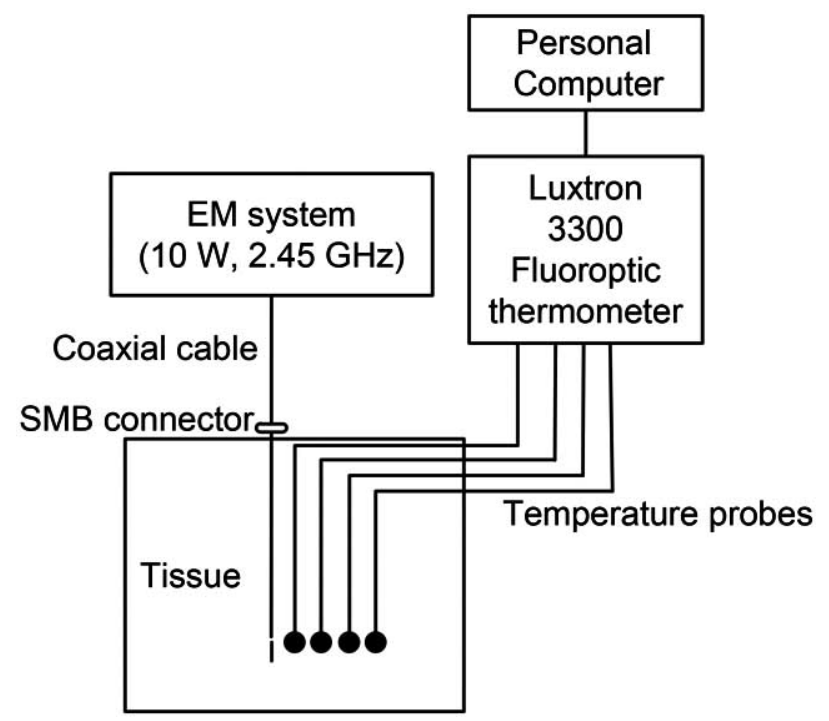

Fig. (13). Schematic of equipment and experimental setup. The antenna was completely inserted into homogeneous muscle tissue and connected to the EM system. Temperature sensors were $5 \mathrm{~mm}$ above the antenna slots longitudinally.

\section{CONCLUSION}

We have developed two models in parallel of an applicator for microwave thermal ablation therapy. The first of these was using commercial software based on FEM. For the other a specific code based on FDTD has been developed. The

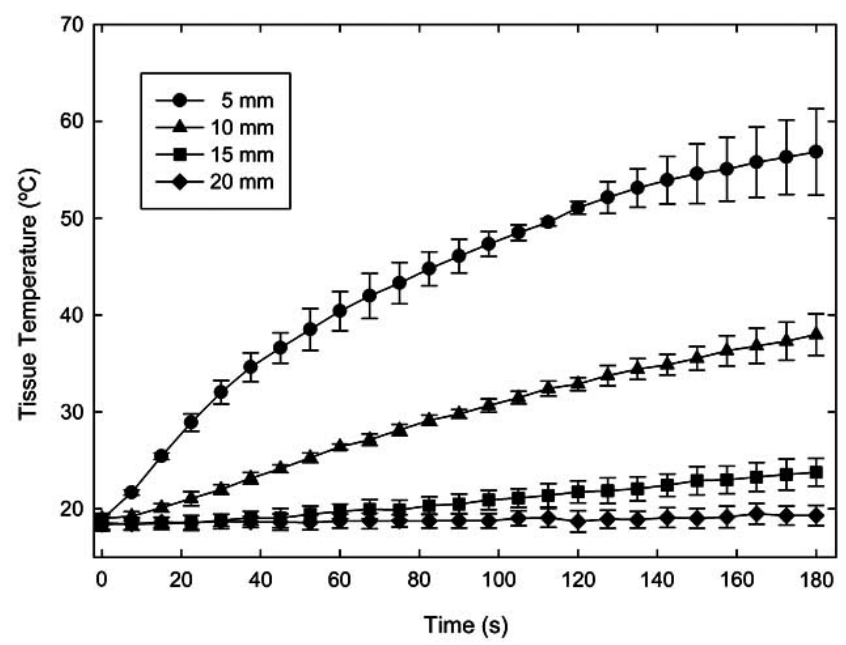

Fig. (14). Plots of measured temperature versus time; temperature sensors were $5 \mathrm{~mm}$ above the antenna slots longitudinally.

potency of the first and versatility of the second method allows complementing and improving the design for a future application. Normalized SAR patterns using FEM and FDTD look broadly similar. Furthermore, the computed $60{ }^{\circ} \mathrm{C}$ isotherm using FEM and the measured lesion diameter in ex vivo tissue results agree very well.

\section{ACKNOWLEDGEMENT}

The authors wish to thank Hugo Zepeda at the CINVESTAV-IPN for his invaluable technical assistance.

\section{REFERENCES}

[1] van der Zee J. Heating the patient: A promising approach? Ann Oncol 2002; 13:1173-84.

[2] Hildebrandt B, Wust P, Ahlers O, et al. The cellular and molecular basis of hyperthermia. Crit Rev Oncol Hematol 2002; 43: 33-56.

[3] Wust P, Hildebrandt B, Sreenivasa G, et al. Hyperthermia in combined treatment of cancer. Lancet Oncol 2002; 3: 487-97.

[4] van Esser S, van den Bosch MA, van Diest PJ, Mali WT, Borel Rinkes IH, van Hillegersberg R. Minimally invasive ablative therapies for invasive breast carcinomas: an overview of current literature. World J Surg 2007; 31: 2284-92.

[5] Riadh W, Habash Y. Bioeffects and therapeutic applications of electromagnetic energy. Taylor \& Francis Group: USA 2008.

[6] Gabriel C. The dielectric properties of biological tissues. I. literature survey. Phys Med Biol 1996; 41: 2231-49.

[7] Yee KS. Numerical solution of initial boundary value problems involving Maxwell's equations in isotropic media. IEEE Trans Ant Prop 1966; AP-14: 302-7.

[8] Sullivan D. Three-dimensional computer simulation in deep regional hyperthermia using the finite-difference timedomain method. IEEE Trans Microw Theory Tech 1990; 38: 204-11.

[9] Haemmerich D, Chachati L, Wright AS, Mahvi DM, Lee FT, Webster JG. Hepatic radiofrequency ablation with internally cooled probes: Effect of coolant temperature on lesion size. IEEE Trans Biomed Eng 2003; 50: 493-500.

[10] Bertram JM, Yang D, Converse MC, Webster JG, Mahvi DM. Antenna design for microwave hepatic ablation using an axisymmetric electromagnetic model. Biomed Eng Online 2006; 5: 15.

[11] Yang D, Bertram J, Converse M, Webster JG, Hagness SC, Mahvi DM. A floating sleeve antenna yields localized hepatic microwave ablation. IEEE Trans Biomed Eng 2006; 53(3): 533-7.

[12] Wissler EH. Pennes' 1948 Paper revisited. J Appl Physiol 1998; 85(1): 35-41.

[13] Nevels RD, Arndt GD, Raffoul GW, Carl JR, Pacifico A. Microwave catheter design. IEEE Trans Biomed Eng 1998; 45: 885-90. 
[14] An Internet resource for the calculation of the dielectric properties of body tissues in the frequency range $10 \mathrm{~Hz}-100 \mathrm{GHz}$ [homepage on the Internet]. Florence, Italy. Institute for Applied Physics "Nello Carrara", Available from: http://niremf.ifac.cnr.it/tissprop/
[15] Ávila-Navarro E, Blanes JM, Carrasco JA, Reig C, Navarro EA. A new bi-faced log-periodic printed antenna. Microw Opt Technol Lett 2006; 48(2): 402-5.

(C) Rubio et al.; Licensee Bentham Open.

This is an open access article licensed under the terms of the Creative Commons Attribution Non-Commercial License (http://creativecommons.org/licenses/by-nc/3.0/) which permits unrestricted, non-commercial use, distribution and reproduction in any medium, provided the work is properly cited. 